\title{
Effects of Once-a-week Interval Training Based on Body Mass Index and Exercise Frequency
}

\author{
Yonghwan Kim', Haemi Jee ${ }^{2^{*}}$ \\ 'Seoul National University, Seoul, Korea \\ ${ }^{2}$ Namseoul University, Cheonan, Korea
}

Received: January 24, 2018

Accepted: April 23, 2018

Published online: April 30, 2018

Keywords:

Body composition

Body mass index

High intensity interval training

Physical fitness

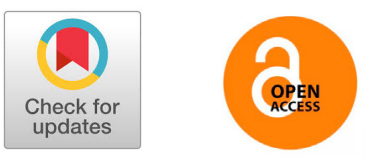

\begin{abstract}
PURPOSE The purpose of this study was to analyze the effects of exercise habit and body mass index(BMI) on once-a-week high intensity interval training (HIIT) in young females. 30 college-aged participants conducted a 60-minute exercise program for 12 weeks.

METHODS Questionnaires on exercise habit, body composition analysis, physical fitness tests were conducted before and after 12 weeks. The training intensity was set to peak HR of $85 \%$ or more, and the program consisted muscular strengthening exercises using weight training tools, props, and a gymball. Time of exercise and rest between exercises were both 30 seconds. Participants were divided by BMI(lower $\mathrm{BMI}(\mathrm{n}=15)$ and higher $\operatorname{BMI}(n=15))$ and the groups were further divided into the lower and higher activity groups by the number of regularly performed exercise days per week(lower -activity $(n=17) 0-2$ days and higher-activity $(n=13)=3$ days.

RESULTS As results, the lower BMI group showed a significant reduction in BMI $\left(\mathrm{kg} / \mathrm{m}^{2}\right)$ and the higher BMI group showed significant improvements in all body components including BMI $\left(\mathrm{kg} / \mathrm{m}^{2}\right)$, body fat $(\%)$, and percent body fat(\%) after the intervention. In the case of physical fitness changes based on lower and higher BMI, both groups showed significant improvements in grip strength $(\mathrm{kg})$, vertical jump $(\mathrm{cm})$, and squat(sec). As for exercise frequency, BMI, body fat and body fat percentage were significantly decreased, and the muscle percentage was significantly increased in the higher-activity group. In the lower-activity group, body weight and BMI decreased significantly.

CONCLUSIONS In conclusion, young healthy females with higher BMI and activity level tend to show greater changes in body composition and physical fitness level.
\end{abstract}

๑ The Asian Society of Kinesiology and the Korean Academy of Kinesiology

\section{서론}

고강도 인터벌 트레이닝(HIIT; high intensity interval training)은 연구자들 마다 조금씩 다른 기준을 적용하지 만, $\mathrm{VO}_{2}$ peak $90 \%$ 수준의 단기간 높은 운동과 휴식을 병행 하는 것을 의미한다(Gibala \& McGee, 2008). 몇 십 초부터 몇 분의 짧은 운동을 하는 운동시간과 완전 휴식 또는 저

*Correspondence: Haemi Jee, Departmment of Sports and Health Care, Namseoul University, 91, Daehak-ro Seonghwan-eup Seobuk-gu, Cheonan, Chungcheongnam-do, 31020, Republic of korea.

E-mail: amyjee@nsu.ac.kr
강도 휴식을 하는 시간을 반복적으로 하게 된다(Shiraev \& Barclay, 2012). 이러한 형식은 전통적으로 휴식과 운동이 반복하는 운동 종목에 참여하는 선수들의 체력을 높이기 위해 적용하였던 방법이지만, 점차 그 적용 범위가 다양 해져 당뇨, 대사성 질환 및 노인들에게 까지 실시하고 긍 정적인 연구 결과를 보고하고 있다(De Araujo et al., 2012; Dunstan et al., 2002; Weston et al., 1996).

HIIT는 단시간에 고강도를 시행함으로써 에너지 소비 를 높이고, 근력운동과 병행 할 수 있다는 점 때문에 운동 시간은 부족하고 높은 효율을 기대하는 일반인과 비만인 들 에게도 많이 시행되고 있다(Gillen \& Gibala, 2013). 최근 
에는 소위 ‘몸짱' 열풍으로퍼스널 트레이닝을 많이 하 고 있으며, 크로스핏(crossfit)등의 형태의 운동이 HIIT 방 식이 적용된 사례라고 할 수 있겠다(Smith et al., 2013). 이 런 트레이닝은 용어에서 의미하듯 고강도이기 때문에 초 보자가 적응기 없이 하기에는 부상과 잠재 질환에 노출될 위험이 높다(Meyer et al., 2017). 운동의 향상 단계는 적응 기와 향상기가 있으며, 적응기는 적 게는 1 개월에서 3 개월 까지 소요된다.

선행 연구에 따르면 인체가 운동에 적응하기 위해서는 최소 2-6주의 시간을 필요하며, 특히 적응기에는 근비대 의 향상보다는 근신경계의 적응이 되는 기간이므로 운동 시작과 동시에 선형적 증가를 하기보다는 처음에는 향상 이 느리다가 적응 후부터 운동의 효과가 증가하게 된다 (Gibala et al., 2006). 운동 지침으로 많이 적용되는 미국스 포츠의학회(ACSM)에서는 비질환자 일반인 건강을 위해 저강도는 주 5 일, 중-고강도의 운동은 주 3 일 이상 할 것을 권장한다(American College of Sports Medicine, 2013). 하지 만, 사람들은 운동의 중요성과 필요성은 인식하는 데 비 해 시간이 없다는 이유로 운동의 참여율이 낮다(Ministry of Culture, Sports and Tourism, 2012).

권장량에 따른 운동 프로그램의 효과에 대한 연구는 많이 발표되었지만 주 1 회 고강도 트레이닝이 젊은 여성 들에 있어서 체력유지와 체성분 관리에 얼마나 효과적인 지는 명확히 밝혀지지 않고 있다. 이러한 연구는 바쁜 현 대 여성들에 게 최소한의 건강관리를 위한 대안을 제안할 수 있을 것이다. 또한 규칙적으로 수행된 운동과 체구성 관리가 새로운 운동에 어떠한 영향을 미치는지 확인하여 규칙적인 관리의 중요성에 대한 정보를 제공할 수 있을 것이다.

따라서, 바쁜 현대인에서 주 3 일 이상 하지 못 할지라 도 주 1 일의 고강도 트레이닝의 효과가 어떻게 나타나 는지 확인하고자 하였으며, 이러한 효과가 정상범위의 $\mathrm{BMI}\left(18.5-22.9 \mathrm{~kg} / \mathrm{m}^{2}\right)$ 를 가진 여대생을 대상으로 상대적 으로 BMI가 높은 사람과 낮은 사람간의 차이가 있지 본 연구를 통해 확인하려 한다. 또한, 기존의 규칙적인 운동 습관 항목인 운동주기(<주당 2일 vs =3일)가 주 1 일 HIIT 을 12 주 동안 할 경우 트레이닝에 얼마나 신체구성과 체 력 향상에 영향을 미치는지도 동시에 확인하여 준비된 신 체구성과 운동주기가 얼마나 건강관리에 영향을 주는지 분석하고자 한다.

\section{연구방법}

\section{연구대상}

본 연구는 건강한 20 대 초반 여성을 대상으로 하였으 며, 본 연구의 목적에 맞게 BMI $25 \mathrm{~kg} / \mathrm{m}^{2}$ 이하이면서, 일주 일에 1회 60 90분을 정기적으로 참여 할 수 있는 사람을 대상으로 하였다. 프로그램 참여 전 본 연구의 목적과 방 법 등 연구의 취지를 충분히 설명하고 연구에 참여할 의 사를 보일 경우 구두와 서명을 통해 연구 참여에 대한 동 의를 얻었다. 사전에 고강도를 인지시켰으며, 사전 설문 을 통해 근골격적 문제가 없으며, 심혈관 병력이 없는 사 람들을 대상으로 실시하였다. 연구의 목적과 함께 정확한 측정을 위해 측정과 운동 중 주의사항을 설명하였다. 이 에는 연구 기간동안 체성분 측정과 운동 수행력에 영향을 줄 수 있는 과도한 음식섭취, 수분섭취, 심한 운동, 설사 여 부 등을 보고하도록 하였다. 이에 더불어 규칙적인 식단 과 칼로리 제한을 위해 식단을 제공하였다. 이에는 또한, 설문에는 운동 시간, 빈도, 강도 등이 포함된 운동 습관 설 문, 미참여 이유, 참여 목적 등이 포함되었다. 체성분 검사 와 체력검사를 실시하였으며, 실험기간 중 가능한 고강도 활동 및 운동 참여를 자제하도록 하였다. 최초 모집자는 34 명이었으며 개인사정으로 인해 중도 이탈된 4 명을 제 외한 최종까지 지속된 30 명이 최종 분석 대상이 되었다.

$\mathrm{BMI}$ 에 따른 트레이닝의 따른 신체구성과 체력의 영 향을 확인하기 위해, 대상자들을 $\mathrm{BMI}$ 에 따른 그룹은 $\mathrm{BMI}$ 의 중앙값(median value)을 기준으로 15 명씩 그룹 을 형성하였으며, 상대적으로 낮은 $\mathrm{BMI}$ 군은 저체중군 (lower $\mathrm{BMI}(\mathrm{n}=15)$ )으로 높은 $\mathrm{BMI}$ 군은 고체중군(higher $\operatorname{BMI}(\mathrm{n}=15))$ 으로 나누어 트레이닝의 효과를 비교하였 다. 저체중군의 $\mathrm{BMI}$ 는 $20.3 \pm 0.7 \mathrm{~kg} / \mathrm{m}^{2}$ 과 고체중군 $(\mathrm{n}=15)$ $21.8 \pm 1.6 \mathrm{~kg} / \mathrm{m}^{2}$ 이었으며 유의한 차이를 보였다. 규칙적인 운동습관이 HIIT에 미치는 영향을 확인하기 위해 연구 참 석자들을 미국스포츠의학회 운동빈도 권고사항(<주당 2 일 vs $=3$ 일 $)$ 을 기반으로 저활동군(lower exercise $(\mathrm{n}=17)$ )과 고활동군(higher exercise $(\mathrm{n}=13))$ 으로 구분하였다.

운동 트레이닝 전 운동 전 평가(pre-exercise evaluation) 를 실시한 후 12 주간 지속될 운동에 대한 자세 교육, 근력 운동 사용법, $1 \mathrm{RM}$ 을 측정하여 본인에게 적합한 무게가 설정되도록 하였다. 탄력밴드와 짐볼, 아령 등은 다양한 크기와 무게, 강도를 준비하였다. 자세한 운동 프로그램 과 휴식시간은 표 1 에서 기술되어 있다<Table 1>. 12주 운 


\begin{tabular}{|c|c|}
\hline Variables & Subjects $(n=30)$ \\
\hline Age (years) & $20.5 \pm 1.5$ \\
\hline Height (cm & $161.0 \pm 4.9$ \\
\hline Weight (kg) & $55.6 \pm 5.8$ \\
\hline BMI $\left(\mathrm{kg} / \mathrm{m}^{2}\right)$ & $21.4 \pm 1.4$ \\
\hline Muscle mass (kg) & $20.9 \pm 2.4$ \\
\hline Muscle ratio (\%) & $37.8 \pm 3.3$ \\
\hline Fat mass $(\mathrm{kg})$ & $15.7 \pm 3.4$ \\
\hline Fat ratio (\%) & $28.0 \pm 4.3$ \\
\hline \multicolumn{2}{|l|}{ Physical activity (n) } \\
\hline 0 & 3 \\
\hline $1-2$ & 14 \\
\hline $3-7$ & 13 \\
\hline \multicolumn{2}{|l|}{ Barrier to exercise $(n)$} \\
\hline Hardness & 10 \\
\hline No time & 6 \\
\hline Not interested & 7 \\
\hline Others: sweat, sleep, condition, etc. & 7 \\
\hline \multicolumn{2}{|l|}{ Purpose of exercise (n) } \\
\hline Weight loss, diet & 14 \\
\hline Physical fitness & 6 \\
\hline Interest, fun & 5 \\
\hline Others: indigestion, no answer, etc. & 5 \\
\hline
\end{tabular}

동 프로그램이 종료된 후 바로 운동 후 평가(post-exercise evaluation)을 사전 검사와 같이 동일한 방법으로 실시하 였다. 또한, 강도 훈련의 특성상 안전을 위해 모든 지도자 는 심폐소생술(CPR) 교육을 이수한 운동전문가들로 구 성하였으며, 만약의 사고에 대비해 응급상황 연락처 방 법 및 자동 제세동 사용법을 포함한 $\mathrm{CPR}$ 사전 모의 훈련 을 실시하였다.

\section{실험절차}

체성분 측정 체성분 분석은 임피던스 방식을 이용한 Inbody 770(Biospace, Korea)의 제품을 사용하여 측정하였 다. 피부의 땀 및 이물질, 각질 등에 따른 오염을 고려하여 손발을 알코올로 세정하였으며, 건조상태에 따른 값의 오 차를 줄이기 위해 해당 회사에서 제공된 전해질 물티슈를 이용하여 손발을 닦은 후 시행하였다. 검사 전후의 정확 도를 위해 측정 시간대를 같게 하였다.
체력검사 모든 실험은 약 2개월간 아침 07:00 10:00에 측정하였다. 피험자들은 실험 전날 24 시간 이상 과도한 운동을 피하고 알콜 섭취를 제한하도록 하였으며 최소 12 시간 이상 금식하였다. 또한 실험 3일전부터는 신체활 동과 식이섭취의 내용을 기록하도록 하였으며, 실험 전 날 저녁 18:00 19:00에 빵(삼립전통크림빵, $230 \mathrm{Kcal}$, 탄수 화물 $36 \mathrm{~g}$, 단백질 $4 \mathrm{~g}$, 지방 $9 \mathrm{~g}$ ) 2 개와 우유 $500 \mathrm{ml}$ (남양 $\mathrm{GT}$, $70 \mathrm{Kcal}$, 탄수화물 $5 \mathrm{~g}$, 단백질 $3 \mathrm{~g}$, 지방 $4 \mathrm{~g}$ )의 총 $530 \mathrm{Kcal}$ 를 피험자 전원에게 제공하여 동일한 영양소와 칼로리를 섭 취하도록 하였다.

악력 악력측정계(Takei 5401, Japan)을 이용하여 악력 (grip strength)을 측정하였으며, 발은 어깨넓이, 상완은 자 연스럽게 내린 채로 서도록 하였다. 악력기를 가운데 손 가락의 2 번 중지골에 맞추어 조정을 하였고, 측정기를 잡 은 손이 주먹이 하나 들어갈 정도의 공간을 두고 서도록 하였다. '시작' 이라는 구령과 함께 힘을 쓰도록 하였 으며 약 2 초간 최대근력을 발휘하도록 하였다. 모든 검사 는 우측과 좌측 2 회씩 실시하여 가장 높게 나온 결과를 기 록하였으며, 키로그램 $(\mathrm{kg})$ 단위로 소수점 한 자리까지 기 록하였다.

수직뛰기 수직뛰기 측정 계(Takei 5406, Japan)를 이용하 였다. 피험자는 측정계 발판 위에 어깨넓이로 서도록 하 였으며, 발구름을 제외한 무릎의 반동을 주지 않도록 지 시하였고 '시작' 과함께 최대한 수직위로 높이 뛰도록 하였다. 2 회 측정 중 높은 값을 기록하였다. 기록은 센티 미터 $(\mathrm{cm})$ 로 하였으며, 소수점 한 자리까지 기록하였다.

무릎 끓고 팔굽혀펴기 상지 근지구력(upper body endurance)을 측정하기 위해 무릎 꼻고 팔굽혀펴기(modified push-up)를 실시하였다. 무릎을 땅에 대고 무릎부터 어깨까지 일직선이 되도록 하였으며, 땅을 짚은 손은 어 깨와 수직이 되도록 하였다. 팔이 약 90 도까지 구부러진 상태를 1 회로 간주 하였으며, 시간제한 없이 최 대한 할 수 있는 개수를 측정하였다. 허리가 구부러짐, 엉덩이가 내 려감, 팔이 충분히 구부러지지 않는 상태를 종료기준으 로 하였다.

정적 스쿼트 하지 근지구력(lower body endurance)을 측정하기 위해 정적 스쿼트(static squat)를 실시하였다. 양 


\begin{tabular}{|c|c|c|c|c|c|}
\hline \multirow{2}{*}{ Variables } & \multicolumn{2}{|c|}{ Lower BMI ( $n=15)$} & \multicolumn{2}{|c|}{ Higher BMI ( $n=15)$} & \multirow[b]{2}{*}{$p(T \times G)$} \\
\hline & Pre & Post & Pre & Post & \\
\hline Age (years) & $20.0 \pm 1.4$ & - & $20.9 \pm 1.5$ & - & - \\
\hline Height (cm) & $159.8 \pm 4.3$ & - & $162.3 \pm 5.5$ & - & - \\
\hline Weight (kg) & $51.8 \pm 3.3$ & $51.0 \pm 3.5$ & $59.5 \pm 5.4^{5}$ & $58.2 \pm 6.1^{5}$ & $<0.001^{\dagger}$ \\
\hline $\mathrm{BMI}\left(\mathrm{kg} / \mathrm{m}^{2}\right)$ & $20.3 \pm 0.7$ & $19.9 \pm 0.7^{*}$ & $22.5 \pm 1.0^{5}$ & $21.9 \pm 1.3^{* \mathrm{v}}$ & $<0.001^{\dagger}$ \\
\hline Muscle mass (kg) & $20.1 \pm 1.8$ & $20.4 \pm 1.0$ & $21.9 \pm 2.6$ & $22.5 \pm 2.6^{5}$ & $0.040^{\dagger}$ \\
\hline Muscle ratio (\%) & $38.9 \pm 3.7$ & $40.1 \pm 3.1$ & $36.8 \pm 2.6$ & $38.8 \pm 2.6^{*}$ & 0.166 \\
\hline Fat mass (kg) & $13.7 \pm 3.1$ & $12.7 \pm 3.4$ & $17.8 \pm 2.3^{\S}$ & $15.8 \pm 3.5^{* 5}$ & $0.010^{\dagger}$ \\
\hline Fat ratio (\%) & $26.3 \pm 4.7$ & $24.5 \pm 5.1$ & $29.9 \pm 3.2^{\S}$ & $27.1 \pm 4.8^{*}$ & 0.106 \\
\hline
\end{tabular}

$\mathrm{p}<0.05$; * paired t-test pre vs. post, §: independent t-test, $\mathrm{t}$ : Repeated two-way ANOVA ( $\times \mathrm{G}$; time $\times$ Group interaction)

발을 어깨 넓이보다 조금 더 넓게 서고, 무릎과 고관절이 90 도가 되도록 앉은 상태에서 양팔은 앞으로 나란히 하도 록 하였다. 최대한 오래 버티기를 1회 측정하였으며, 기록 은 초(second)로 하였다.

눈감고 외발서기 평형성(balance)을 측정하기 위해 측정계(Takei 5407, Japan)를 이용하여 눈감고 외발서기 (eyes-closed unilateral stance)를 측정하였다. 양손을 허리 에 두고, 발모양이 있는 발판에 왼발을 먼저 올린 다음 반 대발을 90 도 뒤로 구부리도록 하였다. '시작' 구령과 함께 눈을 감도록 지시하였으며, 종료기준은 눈을 뜨거 나 손이 허리에서 떨어짐, 발이 땅에 닿을 때로 정하였다. 양측 측정하여 더 높은 값을 초(second)로 기록하였다.

\section{자료처리방법}

본 본 연구를 위해 SPSS 21.0 Window 버전을 이용하였 으며, 모든 연속형 변수는 평균과 표준편차로 기록하였 다. 그룹은 BMI에 따른 구분을 하여 2분법으로 나누어서 15 명씩 두 그룹으로 구분하여 분석하였으며, 운동빈도에 따른 분석을 위해서 최근 3 개월 동안 주 3 일 이상 운동을 한다고 기록한 사람들은 고활동자(13명), 2 일 이하 운동 을 한다고 한 사람들은 저활동자(17명)로 구분하였다. 두 그룹간 결과들을 비교하기 전에 모든 변수들이 정규분포 가정을 만족 시키는지 확인하기 위해 Shapiro-Wilk 검정 을 실시하였으며, 그 결과 모든 변수가 정규분포임을 확 인하였다. 두 그룹간의 훈련 전 비교는 독립 t-검증(independent t-test)를 이용하였으며, 그룹별 각각의 훈련 전후 효과는 반복측정 $\mathrm{t}$-검증(paired t-test)를 실시하였다. 시간
에 따른 그룹의 효과를 검정하기 위해 반복측정 분산분석 (repeated two-way ANOVA)을 실시하였다. 모든 유의수준 은 $\mathrm{a}=.05$ 로 하였다.

\section{결과}

피험자 특성 $(\mathrm{n}=30)$ 으로 평균 나이는 $20.5 \pm 1.5$ 세이며, $\mathrm{BMI}$ 는 $21.4 \pm 1.4 \mathrm{~kg} / \mathrm{m}^{2}$, 근육율은 $37.8 \%$, 체지방률은 $28.0 \%$ 이다. 운동주기로는 전혀 하지 않는 사람이 2명, 주 1-2회 실시하는 사람이 10 명, 3 일 이상 실시하는 사람이 10 명이 다. 운동에 방해 요인으로는 힘들다고 생각해서(hardness) 가 8명으로 가장 많았으며, 시간부족(no time)이 4명, 기 타로는 잠(sleep), 땀 흘리는 것(sweat)이 싫어서 등이 있었 다. 운동의 주목적으로는 체중 감량(weight loss), 다이어 트(diet)가 12명으로 가장 많았으며, 체력향상(physical fitness)이 4명, 흥미 및 재미(interest, fun)가 있어서는 3 명이 었다. 기타로는 소화(digestion)를 위해 등이 있었다.

<Table 2>은 BMI에 따른 HIIT 효과를 분석하였다. 나이 는 20.0 과 $20.9 \mathrm{~kg} / \mathrm{m}^{2}$ 로 유의한 차이는 없었으며, 신장 역 시 유의하지 않았다. 두 그룹간의 트레이닝 전 동질성 여 부를 판단하는 독립 t-test 결과 체중과 $\mathrm{BMI}$, 체지방량, 체 지방률은 유의한 차이가 있었으며, 근육양은 $20.1 \pm 1.8 \mathrm{~kg}$ / $\mathrm{m}^{2}$ 과 $21.9 \pm 2.6 \mathrm{~kg} / \mathrm{m}^{2}$ 로 유의하지 않았고, 근육율도 $38.9 \pm 3.7 \%$ 과 $36.8 \pm 2.6 \%$ 로 유의하지 않았다.

운동 전후 효과를 분석한 결과 BMI가 낮은 그룹은 트 레이닝의 효과가 BMI에서 $20.3 \pm 0.7 \mathrm{~kg} / \mathrm{m}^{2}$ 이 $19.9 \pm 0.7 \mathrm{~kg} /$ $\mathrm{m}^{2}$ 로 유의하게 변하였지만, 다른 부분에서는 유의한 변 화가 나타나지 않았다. 반면, $\mathrm{BMI}$ 가 높은 그룹에서는 
Table 3. Physical fitness changes according to body mass index (BMI)

\begin{tabular}{|c|c|c|c|c|c|}
\hline \multirow{2}{*}{ Variables } & \multicolumn{2}{|c|}{ Lower BMI $(n=15)$} & \multicolumn{2}{|c|}{ Higher BMI $(n=15)$} & \multirow[b]{2}{*}{$p(T \times G)$} \\
\hline & Pre & Post & Pre & Post & \\
\hline Grip strength (kg) & $26.0 \pm 2.4$ & $27.6 \pm 2.7$ & $27.2 \pm 2.8$ & $29.6 \pm 5.4^{*}$ & 0.271 \\
\hline Vertical jump $(\mathrm{cm})$ & $32.9 \pm 7.9$ & $40.8 \pm 8.8^{*}$ & $32.5 \pm 4.8$ & $36.9 \pm 5.1^{*}$ & 0.433 \\
\hline Knee push up (reps) & $26.9 \pm 7.6$ & $56.9 \pm 12.8^{*}$ & $24.0 \pm 5.3$ & $58.8 \pm 11.7^{*}$ & 0.892 \\
\hline Static squat (sec) & $50.5 \pm 14.4$ & $80.0 \pm 34.5^{*}$ & $59.1 \pm 10.9$ & $94.3 \pm 28.4^{*}$ & 0.189 \\
\hline Balance (sec) & $41.2 \pm 18.4$ & $87.2 \pm 77.9$ & $44.9 \pm 17.1$ & $70.4 \pm 64.6$ & 0.703 \\
\hline Grip strength per BW & $0.50 \pm 0.05$ & $0.54 \pm 0.06^{*}$ & $0.46 \pm 0.02^{\S}$ & $0.51 \pm 0.08^{*}$ & 0.069 \\
\hline Leg power $(\mathrm{cm} / \mathrm{kg})$ & $1704.8 \pm 402.5$ & $2111.5 \pm 434.4^{*}$ & $1932.5 \pm 338.5$ & $2205.8 \pm 417.9^{*}$ & 0.325 \\
\hline Upper endurance (sec/kg) & $1395.9 \pm 409.5$ & $2946.6 \pm 685.0^{*}$ & $1429.0 \pm 355.4$ & $3506.3 \pm 789.5^{*}$ & 0.193 \\
\hline Lower endurance (sec/kg) & $2609.2 \pm 718.9$ & $4116.7 \pm 1705.7^{*}$ & $3523.1 \pm 768.4$ & $5636.1 \pm 1863.2^{*}$ & $0.021^{\dagger}$ \\
\hline
\end{tabular}

$\mathrm{p}<0.05$; *: paired t-test pre vs. post, §: independent t-test, $\mathrm{t}$ : Repeated two-way ANOVA ( $\mathrm{T} \times \mathrm{G}$; time $\times$ group interaction).

Grip strength per BW; grip strength $(\mathrm{kg})$ divided by body weight $(\mathrm{kg})$, leg power; vertical jump $(\mathrm{cm}) \times$ body weight $(\mathrm{kg})$, upper endurance;: static squat $(\mathrm{sec}) \times$ body weight (kg), lower endurance: static squat (sec) $\times$ body weight $(\mathrm{kg})$

\begin{tabular}{|c|c|c|c|c|c|}
\hline \multirow{2}{*}{ Variables } & \multicolumn{2}{|c|}{ Lower activity ( $n=17)$} & \multicolumn{2}{|c|}{ Higher activity $(n=13)$} & \multirow[b]{2}{*}{$p(T \times G)$} \\
\hline & Pre & Post & Pre & Post & \\
\hline Age (years) & $20.3 \pm 1.5$ & - & $20.7 \pm 1.5$ & - & \\
\hline Height $(\mathrm{cm})$ & $161.0 \pm 4.7$ & - & $161.1 \pm 4.7$ & - & \\
\hline Weight (kg) & $54.8 \pm 5.8$ & $53.8 \pm 5.4^{*}$ & $56.7 \pm 5.8$ & $55.5 \pm 5.4$ & 0.489 \\
\hline $\mathrm{BMI}\left(\mathrm{kg} / \mathrm{m}^{2}\right)$ & $21.1 \pm 1.6$ & $20.6 \pm 1.4^{*}$ & $21.8 \pm 1.6$ & $21.2 \pm 1.4^{*}$ & 0.303 \\
\hline Muscle mass (kg) & $20.9 \pm 1.9$ & $21.2 \pm 1.8$ & $21.2 \pm 1.9$ & $21.8 \pm 1.8$ & 0.658 \\
\hline Muscle ratio (\%) & $38.2 \pm 3.4$ & $39.6 \pm 3.4$ & $37.3 \pm 3.4$ & $39.3 \pm 3.4^{*}$ & 0.648 \\
\hline Fat mass $(\mathrm{kg})$ & $15.3 \pm 4.0$ & $14.0 \pm 4.3$ & $16.3 \pm 4.0$ & $14.5 \pm 4.3^{*}$ & 0.629 \\
\hline Fat ratio (\%) & $27.6 \pm 5.3$ & $25.6 \pm 6.3$ & $28.7 \pm 5.3$ & $25.9 \pm 6.3^{*}$ & 0.730 \\
\hline
\end{tabular}

$\mathrm{p}<0.05 ;$ : paired t-test pre vs. post, $\S:$ independent t-test, $\mathrm{t}$ : Repeated two-way ANOVA (T $\times \mathrm{G}$ : time $\times$ group interaction)

$\mathrm{BMI}$, 근육율 $(\%)$, 체지방량 $(\mathrm{kg})$, 체지방률(\%)이 유의하 였다. $\mathrm{BMI}$ 는 $22.5 \pm 1.0 \mathrm{~kg} / \mathrm{m}^{2}$ 이 $21.9 \pm 1.3 \mathrm{~kg} / \mathrm{m}^{2}$, 근육율 은 $36.8 \pm 2.6 \%$ 가 $38.8 \pm 2.6 \%$, 체지방량은 $17.8 \pm 2.3 \mathrm{~kg}$ 이 $15.8 \pm 3.5 \mathrm{~kg}$, 체지방률이 $29.9 \pm 3.2 \%$ 가 $27.1 \pm 4.8 \%$ 로 유의 한 차이를 나타내었다. 그룹간의 변화를 나타낸 분석 결 과 체중 $(\mathrm{p}=<0.01), \mathrm{BMI}(\mathrm{p}<0.01)$, 근육량 $(\mathrm{p}=0.04)$, 체지방량 $(\mathrm{p}=0.01)$ 이 유의하게 차이가 있었다.

$\mathrm{BMI}$ 에 따른 체력의 변화는 두 그룹 대부분의 영역에 서 나타났다<Table 2>. 눈감고 외발서기는 두 그룹에서 유의하지 않았다. 악력은 각 그룹에서 $26.0 \pm 2.4 \mathrm{~kg}$ 에서 $27.6 \pm 2.7 \mathrm{~kg}, 27.2 \pm 2.8 \mathrm{~kg}$ 에서 $29.6 \pm 5.4 \mathrm{~kg}$ 으로 유의한 향 상이 있었다. 제자리 높이뛰기는 각 그룹에서 $32.9 \mathrm{~cm}$ 에 서 $40.8 \mathrm{~cm}, 32.5 \mathrm{~cm}$ 에서 $36.9 \mathrm{~cm}$ 로 유의한 향상이 있었으며,
하지근력 검사인 스쿼트 오래 버티기에서도 각 그룹에서 50.5 초에서 $80.0,59.1$ 초에서 94.3 초로 유의한 향상이 있었 다.

최근 3 개월간 신체활동 빈도(<주당 2 일 vs $=3$ 일)에 따 른 그룹을 나누어 신체구성과 활동량을 분석하였다. $<\mathrm{Ta}-$ ble $3>$ 과 같이 저활동 군에서는 체중과 $\mathrm{BMI}$ 의 유의한 변 화가 있었지만, 근육량과 근육율, 체지방량과 체지방율 에서는 유의한 차이를 나타내지 못하였다. 고활동 군에서 는 $\mathrm{BMI}$, 근육율, 체지방량, 체지방률에서 유의한 변화를 나타내었으며, 근육양은 증가하고, 체지방량은 감소하는 긍정적 변화를 유발하였다. 고활동군의 근육율은 $37.3 \%$ 에서 $39.3 \%$ 으로 증가하였으며, 반면 체지방률은 $28.7 \%$ 에 서 $25.9 \%$ 로 감소하였다. 
Table 5. Physical fitness changes according to exercise frequency

\begin{tabular}{|c|c|c|c|c|c|}
\hline \multirow{2}{*}{ Variables } & \multicolumn{2}{|c|}{ Lower activity ( $n=17$ ) } & \multicolumn{2}{|c|}{ Higher activity ( $n=13$ ) } & \multirow[b]{2}{*}{$p(T \times G)$} \\
\hline & Pre & Post & Pre & Post & \\
\hline Grip strength $(\mathrm{kg})$ & $25.9 \pm 1.9$ & $27.8 \pm 2.8^{*}$ & $27.5 \pm 1.9$ & $29.6 \pm 2.8^{*}$ & 0.236 \\
\hline Vertical jump (cm) & $31.0 \pm 6.4$ & $38.2 \pm 8.1^{*}$ & $34.7 \pm 6.4$ & $39.7 \pm 8.1^{*}$ & 0.348 \\
\hline Knee push up (rep) & $25.8 \pm 3.7$ & $57 \pm 12.4^{*}$ & $25.1 \pm 3.7$ & $58.9 \pm 12.4^{*}$ & 0.866 \\
\hline Static squat (sec) & $55.0 \pm 15.1$ & $94.9 \pm 28.3^{*}$ & $54.5 \pm 15.1$ & $77.8 \pm 28.3^{*}$ & 0.319 \\
\hline Balance (sec) & $40.3 \pm 19.4$ & $69.2 \pm 77.1$ & $46.3 \pm 19.4$ & $90.3 \pm 77.1$ & 0.429 \\
\hline Grip strength per BW & $0.48 \pm 0.04$ & $0.52 \pm 0.06^{*}$ & $0.50 \pm 0.01$ & $0.50 \pm 0.03^{*}$ & 0.582 \\
\hline Leg power $(\mathrm{cm} / \mathrm{kg})$ & $1699.8 \pm 381.2$ & $2087.2 \pm 449.8^{*}$ & $1961.3 \pm 381.2$ & $2244.3 \pm 449.8^{*}$ & 0.198 \\
\hline Upper endurance (sec/kg) & $1423.3 \pm 328.6$ & $3145.9 \pm 881.3^{*}$ & $1399.4 \pm 328.6$ & $3323.0 \pm 881.3^{*}$ & 0.742 \\
\hline Lower endurance (sec/kg) & $3032 \pm 939.1$ & $5229.3 \pm 1759.4^{*}$ & $3107.1 \pm 939.1$ & $4452.8 \pm 1759.4^{*}$ & 0.533 \\
\hline
\end{tabular}

저활동군에서는 대체로 변화가 없었고, 고활동군에서 는 대체로 변화하였지만 두 그룹간에 유의한 차이는 어느 부분에서도 나타나지 않았으며, 가장 낮은 $\mathrm{p}$-값이 $\mathrm{BMI}$ 에 서 0.30 이었다.

$<$ Table 4 >와 같이 체력의 변화에서는 낮은 신체활동 군 에서는 비록 체구성의 변화는 없었지만, <Table 5>에서 와 같이 체력의 변화는 있었다. 두 그룹 모두 평형성 (balance)을 제외한 모든 부분에서 훈련 전후로 유의한 변화 가 있었다. 악력(grip strength)은 각각의 그룹에서 25.9에 서 $27.8 \mathrm{~kg}, 27.5 \pm 1.9$ 에서 $29.6 \pm 2.8 \mathrm{~kg}$ 로 향상되었으며, 제 자리 높이 뛰기는 31.0 에서 $38.2 \mathrm{~cm}, 34.7$ 에서 $39.7 \mathrm{~cm}$ 로 향 상 되었다. 무를 꼻고 팔굽혀펴기(knee push-up)과 정적 스 쿼트(static squat) 또한 그룹별 유의한 향상을 보였다.

반복측정 분산분석 결과는 다음과 같다. 시간과 그룹 의 교차효과를 검정한 결과는 $\mathrm{BMI}$ 를 기준으로 분석 하였 을 때만 나타났으며, 체중 $(\mathrm{p}<0.001), \mathrm{BMI}(\mathrm{p}<0.001)$, muscle $\operatorname{mass}(\mathrm{p}=0.40)$, fat mass $(\mathrm{p}=0.017)$, 하지 근지구력(lower endurance)에서 유의한 결과를 나타내었다.

\section{논의}

이번 연구는 모집된 젊은 여성들을 대상으로 주 1 회 고 강도 인터벌 트레이닝(HIIT)을 실시하였으며, 12주간 지 속하여 동일한 운동을 적용하였다. 먼저, $\mathrm{BMI}$ 를 기준으로 모집된 집단을 중앙값을 기준으로 두 그룹으로 나누어 분 석하였다. 과연 $\mathrm{BMI}$ 가 높은 사람들에 게 운동효과가 좋은
지 낮은 사람들한테 효과가 좋은지에 대해 분석하기 위함 이었다. 이 후 운동습관에 따른 HIIT의 효과를 확인하기 위해 그룹은 기존의 운동 주기를 기준으로 저강도 및 고 강도 운동군으로 구분하여 그 결과를 확인하였다.

일반적으로 권고되고 있는 운동 기준은 기존 다양한 연구를 통해 확인되었다. 미국스포츠의학회(ACSM)에서 권장하는 운동 일수는 중등강도로 운동을 하였을 경우 5 일 이상, 고강도로 운동을 하였을 경우 주 3 일 이상이다 (American College of Sports Medicine, 2013). 하지만, 현대 인은 매우 바쁜 삶을 살고 있으며, 시간이 없다는 이유로 운동 참여를 미루는 것도 현실이다. 2012년도 정부 기관 에서 실시한 연구에 따르면 운동을 하지 않는 이유 중 20 대에서는 운동을 전혀 하지 않는 사람들이 $67.3 \%$ 이었으 며, 운동하지 않은 이유로 $48.7 \%$ 의 사람들이 시간 부족을 운동불참의 이유로 가장 많이 지목하였다. 두 번째 이유 로는 관심이 없어서로 $30.1 \%$ 가 운동불참의 원인으로 지 목하였다(문화체육관광부, 2012). 동일한 연구에서 신체 활동 참여 이유로, $31.3 \%$ 가 건강, $54.3 \%$ 가 체중 조절 및 체 형 관리라고 답을 하였다. 이러한 의미는 건강과 체중 조 절을 위해 운동을 해야 하는데 시간이 없어서 못하는 것 이라고 할 수 있겠다. 본 연구의 구상은 이러한 관점을 갖 고 분석을 시작하였다. 비록 주 1 회 밖에 못하지만 이들에 게 나타나는 효과가 체중, 체지방, 근육량에 어떻게 영향 을 미칠까 라는 의문을 갖고 연구를 실시하였다.

본 연구에 적용되었던 HIIT는 전통적으로 오랫동안 사 용되어 왔던 방법으로서 주로 선수들의 무산소성 기능과 
지구성 능력을 복합적으로 훈련하여 훈련과 경기 상황에 서 높은 수행능력을 유지하고자 했던 부분이다. 하지만, 단시간 고효율이라는 특징으로 인해 다양한 연령층과 질 환군에 게 적용하였다(De Araujo et al., 2012; Dunstan et al., 2002; Weston et al., 1996). 오랜기간 동안 HIIT의 긍정적 효 과에 대해서는 이미 검증이 되었다. 대부분은 전통적 트 레이닝 보다 효과가 비슷하거나 더 좋은 것으로 설명하고 있다(Zuhl \& Kravitz, 2012). 하지만, 주 1 회 운동을 12주간 실시한 연구에서는 HIIT 그룹이나 전통적 운동방식을 적 용한 그룹이나 체중, BMI 등에는 유의한 변화가 없었고, 체력은 향상되는 것으로 나타났다고 하는 연구도 있었다

(Roxburgh, et al, 2014). 하지만, 시간의 효율성이 매우 좋은 운동인 것은 분명해 보인다(Gillen \& Gibala, 2013).

이러한 기존의 지속적으로 다양한 연구결과에서 벗어 나 본 연구에서는 바쁜 젊은 여성들에게 적용할 수 있는 주1회 HIITT를 실시한 결과 다음과 같은 결과를 확인하 였다. 첫 번째로, 피험자들을 BMI로 나누어 체력과 신체 구성을 확인해 본 결과, 본 연구에서 대체로 결과는 $\mathrm{BMI}$ 가 높은 사람들에 게서 더 좋은 효과가 나타났다. 체중은 낮은 $\mathrm{BMI}$ 그룹이 $0.8 \mathrm{~kg}$ 빠진 반면, 높은 $\mathrm{BMI}$ 그룹이 $1.3 \mathrm{~kg}$ 감량되었다. 근육량도 $0.3 \mathrm{~kg}$ vs. $0.6 \mathrm{~kg}$ 의 증가 있었고, 체지 방 감소도 $1 \mathrm{~kg}$ vs. $2 \mathrm{~kg}$ 의 감소가 있었다. 체중이 감소가 있 을 시 지방만 빠지는 것이 아니라 근육도 감소되는 경향 이 있음에도 불구하고 본 연구에서는 두 그룹 모두 체중 감소와 함께 지방은 감소하고, 근육은 증가하였다.

이러한 결과가 도출된 데에는 아무래도 BMI가 높을수 록 변화의 가능성과 여지가 많기 때문으로 해석되며, BMI 가 낮은 그룹은 빼야 할 지방도 적기 때문인 것으로 생각 된다. 본 연구가 진행되었던 주된 목적 중 하나인 주 1 회 고강도 운동만으로도 체구성의 변화 효과를 확인할 수 있 었다. 하지만, $\mathrm{BMI}$ 가 높을수록 그 효과가 더 좋은 것으로 나타났다. 선행연구에서도 $\mathrm{BMI} 25.0 \mathrm{~kg} / \mathrm{m}^{2}$ 의 좌업 젊은 여 성들을 대상으로 6주 HIIT를 한 결과 BMI와 체지방의 긍 정적인 유의한 변화가 나타난 것으로 보고되었으며(Kordi et al,, 2013), 크로스핏(crossfit) 트레이닝을 10주 한 결과 $\mathrm{VO}_{2} \max$ 의 향상은 물론 체지방의 유의한 변화를 나타내 었다고 하였다(Smith et al, 2013). 과체중이 여성에서도 비 슷한 결과를 나타내었다(Sijie et al., 2012).

다음은 평상시 운동 습관에 따른 결과 차이에 대한 내 용이다. 운동습관을 운동 주기로 평가하였으며 주당 2 일 와 $=3$ 일로 구분하여 그룹을 나누어 이에 따른 그룹별 신
체구성과 체력을 비교 분석하였다. 본 연구결과에 따르 면 고활동 군에서 더 많은 신체구성의 변화를 보였으며 두 군 모두 체력적 변화를 보였다. 선행연구들에 의하면 규칙적인 운동을 한 신체에서는 근세포 단백질 합성과 미토콘드리아 생합성 등이 촉진되는 적응이 확인되었다 (Coffey, 2006). 즉 규칙적으로 운동한 경험이 있을 경우 운 동에 대한 신체의 반응은 운동을 하지 않을 경우보다 더 크다는 것이다.

선행연구에 따르면 중등강도의 운동을 하여 근육이 적 응하는데 짧아도 2 주 보통 6 주의 시간을 필요로 하는 것 을 되고 있다(Gibala et al, 2006). 근육의 크기의 변화가 아 닌 근신경 시스템의 변화로 인한 근력발현의 차이가 유도 되는 것으로 보고하였다(Akima et al, 1999). 이러한 연구 를 바탕으로 본 연구를 해석한다면 기존의 운동을 하던 사람은 고강도 트레이닝의 적응이 쉽게 이뤄져서 그 효과 도 빠르게 나타난 반면, 평소 운동을 즐겨 하지 않던 사람 들은 최소 몇 주는 적응기에 해당하였으므로 물리적 운동 양은 상대적으로 같았다고 할지라도 그 효과는 다르게 나 타났다고 판단된다. 하지만 운동 기간이 좀 더 길어진 수 개월 진행되었다면 그룹 간의 차이는 본 연구 결과와 같 이 나타나지 않았을 수도 있었을 것이라고 사료된다.

앞서 언급된대로 HIIT의 특징은 고강도이기 때문에 시간의 효율성을 강조하는 부분이 있다(Gillen \& Gibala, 2013). 이러한 방식을 전통적 방식의 지구성 트레이닝과 비교 한 연구들이 다수 있는데, 기존의 트레이닝에 비교 했을 때 에너지 효율성이나 혈당감시(glucose monitoring) 의 결과가 차이가 없음을 설명하였다(Little et al., 2014; Skelly et al., 2014). 이러한 연구 결과들은 운동을 통한 에 너지량을 같게 한다면 소위 말하는 '중등강도 30 분 이 상' 이라는 권장사항에 제한을 둘 필요가 없음을 설명하 는 배경이 된다. HIIT 단기간의 효과를 분석 연구에서 여 성들을 대상으로 2주간 단 7회만 HIIT 트레이닝을 하였을 때 지방 산화능력 근력, $\mathrm{VO}_{2}$ peak의 유의한 증가가 있었다 고 하였다(Talanian et al., 2007). 다른 연구에서도 2 주간 트 레이닝으로도 당뇨가 있는 사람들에게 인슐린 저항성을 측정하는 공복 혈중인슐린 검사인 HOMR-IR 결과의 유의 한 변화를 유발한다고 하였다(Shaban et al., 2014). 사람들 이 운동을 단 몇 주 또는 몇 개월만 하고 안하는 것은 아니 지만, 인내심과 함께 수개월간 지속하지 않아도 단 2주 만 에도 긍정적 결과를 나타내기 때문에 보다 좋은 동기부여 를 제공 할 수 있을 것으로 생각된다. 
하지만, HIIT는 단어에서 의미하듯 고강도이기 때문에 손상의 위험이 항상 있으며, 안전장치 및 전문가의 의견 이 반영되지 않은 상태에서는 더욱 문제가 될 수 있다. 따 라서, 대상에 게 적용하기에 앞서 필요성이 같이 고려되어 야 하겠다. Gibala et al(2008)의 연구에서 언급한대로 “많 은 것을 위해 좀 아파야 할까?" 라는 부분을 생각해야 하 겠으며(Gibala \& McGee, 2008), 대상이 특히 노인 및 심뇌 혈관 질환의 이력 및 가능성이 있는 사람들에 게는 안전성 이 먼저 보장되어야 할 것이다(Carl et al., 2016).

본 연구에서는 반복측정 분산분석 결과 시간과 그룹에 따른 교호효과에 대한 결과가 일부에서만 나타났다. BMI 를 기준으로 분석 하였을 때 체중, $\mathrm{BMI}$, 체지방량, 근육량 에서 나타났다. 이러한 결과를 나타낸데에 는 대조군 없이 모든 사람들에 게 트레이닝을 하였기 때문에 시간에 따른 전후 비교는 유의하지만 그룹 간에 차이가 없는 것으로 생각된다. 또한, 체중, 체지방량, 근육량 등 절 대값만 유의 한 결과를 나타낸 부분도 지방은 줄고, 근육은 증가되었 으나 체중이 감소됨에 따라 상대적인 값에는 큰 변화를 유발하지 않은 것이 원인으로 사료된다.

본 연구의 제한점으로는 참여자의 식이 활동 및 본 실 험 외의 다른 신체활동을 통제하지 않았다는 점이며, 비 교적 참여자의 숫자가 많지 않다는데 있다. 체구성은 체 수분과 식이 활동에 영향을 주기 때문에 연구 초기에 이 에 대한 중요성과 상담을 통해 관리를 하였지만 일반인을 대상으로 통제하는 것은 한계가 있다. 그리고 대상자가 비만인이기 보다는 보통 또는 심지어 마른 사람들이라고 평가되는 사람들이 대부분 이었다. 이러한 연구를 바탕으 로 추가적으로 제안되는 연구는 주 1 회 트레이닝과 주 3 일 또는 주 5일 트레이닝을 실시하여 빈도에 따른 효과 차 이를 검정하는 것도 좋은 연구라고 생각된다. 또한, 대상 자가 여자를 하였는 데, 근육이 상대적으로 많은 남자들에 게 나타나는 반응 또는 근육이 감소하고 있는 노인층에 게 도 실시하여 주 1 회 운동이 효과가 있는지에 대해 검정하 는 것도 필요하다고사료된다.

\section{결 론}

본 연구는 젊은 여성을 대상으로 주 1 회 고강도 인터벌 트레이닝이 $\mathrm{BMI}$ 와 운동습관에 따라 체구성과 체력에 어 떤 영향을 주는지에 대해 알아보고자 하였다. 12 주간, 주 1 회 이지만 HIIT는 체지방 감량과 근육량 향상, 체력의 향
상을 나타났으며, BMI가 높을수록 이러한 현상이 더 잘 나타났다. 또한 운동습관에 따른 차이는 평상시 운동을 참여하는 경우 주 1 회 고강도 운동 시 체구성의 변화 및 체력의 향상에 영향을 주는 것으로 나타났다. 본 연구의 결과는 주 1 회 고강도 운동이 건강한 젊은 여성들에 체력 과 신체구성에 긍정적인 영향을 줄 수 있다라는 것을 제 시하였다.

\section{Conflicts of Interest}

The authors declare no conflict of interest.

\section{References}

Akima, H., Takahashi, H., Kuno, S., Masuda, K., Masuda, T., Shimojo, H., Anno, I., Itai, Y., \& Katsuta, S. (1999). Early phase adaptations of muscle use and strength to isokinetic training. Medicine and Science in Sports and Exercise, 31, 588-594.

American College of Sports Medicine. (2013). ACSM's guidelines for exercise testing and prescription(9th ed.): Philadelphia. Lipponcott Williams and Wilkins.

Carl, D. L., Boyne, P., Rockwell, B., Gerson, M., Khoury, J., Kissela, B., \& Dunning, K. (2016). Preliminary safety analysis of high-intensity interval training (HIIT) in persons with chronic stroke. Applied Physiology, Nutrition, and Metabolism, 42(3), 311-318. Coffey, V. G., Zhong, Z., Shield, A., Canny, B. J., Chibalin, A. V., Zierath, J. R., \& Hawley, J. A. (2006) Early signaling responses to divergent exercise stimuli in skeletal muscle from well-trained humans." The FASEB Journal, 20(1), 190-192.

De Araujo, A. C. C., Roschel, H., PicançO, A. R., do Prado, D. M. L., Villares, S. M. F., de Sa Pinto, A. L., \& Gualano, B. (2012). Similar health benefits of endurance and high-intensity interval training in obese children. PloS One, 7(8), e42747.

Dunstan, D. W., Daly, R. M., Owen, N., Jolley, D., De Courten, M., Shaw, J., \& Zimmet, P. (2002). High-intensity resistance training improves glycemic control in older patients with type 2 diabetes. Diabetes Care, 25(10), 
1729-1736.

Gibala, M. J., Little, J. P., Van Essen, M., Wilkin, G. P., Burgomaster, K. A., Safdar, A., Raha, S., \& Tarnopolsky, M. A. (2006). Short-term sprint interval versus traditional endurance training: similar initial adaptations in human skeletal muscle and exercise performance. The Journal of Physiology, 575(3), 901-911.

Gibala, M. J., \& McGee, S. L. (2008). Metabolic adaptations to short-term high-intensity interval training: a little pain for a lot of gain? Exercise and Sport Sciences Reviews, 36(2), 58-63.

Gillen, J. B., \& Gibala, M. J. (2013). Is high-intensity interval training a time-efficient exercise strategy to improve health and fitness? Applied Physiology, Nutrition, and Metabolism, 39(3), 409-412.

Kordi, M., Choopani, S., Hemmatinafar, M., \& Choopani, Z. (2013). The effects of six weeks high intensity interval training (HIIT) on resting plasma levels of adiponectin and fat loss in sedentary young women. Journal of Jahrom University of Medical Sciences, 11(1), 23-31.

Little, J. P., Jung, M. E., Wright, A. E., Wright, W., \& Manders, R. J. (2014). Effects of high-intensity interval exercise versus continuous moderate-intensity exercise on postprandial glycemic control assessed by continuous glucose monitoring in obese adults. Applied Physiology, Nutrition, and Metabolism, 39(7), 835-841.

Meyer, J., Morrison, J., \& Zuniga, J. (2017). The benefits and risks of crossfit: A systematic review. Workplace Health \& Safety, 65(12), 612-618.

Roxburgh, B. H., Nolan, P. B., Weatherwax, R. M., \& Dalleck, L. C. (2014). Is moderate intensity exercise training combined with high intensity interval training more effective at improving cardiorespiratory fitness than moderate intensity exercise training alone? Journal of Sports Science \& Medicine, 13(3), 702.

Shaban, N., Kenno, K., \& Milne, K. (2014). The effects of a 2 week modified high intensity interval training program on the homeostatic model of insulin resistance (HOMA-IR) in adults with type 2 diabetes. The Journal of
Sports Medicine and Physical Fitness, 54(2), 203-209.

Shiraev, T., \& Barclay, G. (2012). Evidence based exercise: Clinical benefits of high intensity interval training. Australian Family Physician, 41(12), 960.

Sijie, T., Hainai, Y., Fengying, Y., \& Jianxiong, W. (2012). High intensity interval exercise training in overweight young women. The Journal of Sports Medicine and Physical Fitness, 52(3), 255-262.

Skelly, L. E., Andrews, P. C., Gillen, J. B., Martin, B. J., Percival, M. E., \& Gibala, M. J. (2014). High-intensity interval exercise induces 24-h energy expenditure similar to traditional endurance exercise despite reduced time commitment. Applied Physiology, Nutrition, and Metabolism, 39(7), 845-848.

Smith, M. M., Sommer, A. J., Starkoff, B. E., \& Devor, S. T. (2013). Crossfit-based high-intensity power training improves maximal aerobic fitness and body composition. The Journal of Strength \& Conditioning Research, 27(11), 3159-3172.

Talanian, J. L., Galloway, S. D., Heigenhauser, G. J., Bonen, A., \& Spriet, L. L. (2007). Two weeks of high-intensity aerobic interval training increases the capacity for fat oxidation during exercise in women. Journal of Applied Physiology, 102(4), 1439-1447.

Weston, A. R., Myburgh, K. H., Lindsay, F. H., Dennis, S. C., Noakes, T. D., \& Hawley, J. A. (1996). Skeletal muscle buffering capacity and endurance performance after high-intensity interval training by well-trained cyclists. European Journal of Applied Physiology and Occupational Physiology, 75(1), 7-13.

Whyte, L. J., Ferguson, C., Wilson, J., Scott, R. A., \& Gill, J. M. (2013). Effects of single bout of very high-intensity exercise on metabolic health biomarkers in overweight/ obese sedentary men. Metabolism, 62(2), 212-219.

Zuhl, M., \& Kravitz, L. (2012). Hiit vs. continuous endurance training: battle of the aerobic titans. IDEA Fitness Journal, 9(2), 34-40.

Ministry of Culture, Sports and Tourism (2012) 2012 Survey on participation in physical activity in daily life. 